VISITAS AL PATIO Vol.14, No.1 - 2020, ISSN 2248-485X, e-ISSN 2619-4023, pp. 6-26

\title{
De máscaras y demonios: criminalización, heroísmo e identidad racial en El fusilamiento del diablo
}

\author{
M. Alejandra Aguilar Dornelles ${ }^{1}$ \\ Universidad de Albany-SUNY
}

ORCID ID: 0000-0002-9479-8775

Recibido: 12 de enero

Aceptado: 08 de abril

\section{RESUMEN}

Este artículo explora la masculinidad negra heroica creada por Manuel Zapata Olivella (19202004) en su novela El fusilamiento del diablo (1986) sugiriendo que el autor politiza la figura histórica de Manuel Saturio Valencia (1867-1907) para proponer al cuerpo del hombre negro como símbolo de la promesa revolucionaria latinoamericana. El escritor afrocolombiano manipula la figura heroica para que en ella converjan el surgimiento de una conciencia racial fuertemente unida a una conciencia de clase desde la que se funda una genealogía chocoana heroica. Hábilmente el autor desplaza a su protagonista por diferentes escenarios, en diferentes épocas y circunstancias en las que el hombre alterna con el niño, el revolucionario con el dandy, el criminal sediento de venganza con el enamorado. Además, sugiero que Zapata Olivella denuncia en la narrativización del fusilamiento la fragilidad de la ley y su rol en la constitución y mantenimiento de estructuras de privilegio y desigualdad.

Palabras clave: Manuel Zapata Olivella, Manuel Saturio Valencia, masculinidad negra heroica, identidad racial, criminalización de la rebeldía

\begin{abstract}
This article explores the heroic black masculinity created by Manuel Zapata Olivella (1920-2004) in his novel El fusilamiento del diablo (1986) suggesting that the author politicizes the historical figure of Manuel Saturio Valencia (1867-1907) to propose the body of the black man as a symbol of the Latin American revolutionary promise. By making his racial consciousness intersects with his awakening of social oppression, the Afro-Colombian writer manipulates the heroic figure to construct a character as an allegory of the Chocoan identity. Also, Zapata Olivella creates a ubiquitous hero who moves through different scenarios, times, and circumstances in which the man alternates with the child, the revolutionary with the dandy, the criminal thirsty for revenge with the lover. Furthermore, I suggest that through the narrativization of Valencia's execution, Zapata Olivella
\end{abstract}

* Of Masks and Demons: Criminalization, Heroism, and Racial Identity in The Devil's Execution

${ }^{1} \mathrm{Ph}$. D. in Romance Languages and Literatures, Universidad de Washington en St. Louis. Profesora Asistente en Estudios hispánicos e italianos de la Universidad de Albany, Estados Unidos. Correo:maguilardornelles@albany.edu 
denounces the fragility of the law and its role in the constitution and maintenance of structures of privilege and social inequality.

Keywords: Manuel Zapata Olivella, Manuel Saturio Valencia, heroic black masculinity, racial identity, criminalization of rebellion

La mañana del primero de mayo de 1907 los vecinos de Quibdó, capital de Chocó en el Pacífico colombiano, despertaron alarmados por gritos que anunciaban fuego. Estupefactos vieron que las casas de una de las calles principales del pueblo ardían en llamas. Luego de controlar el incendio, las autoridades apresaron al poeta y juez de paz afrodescendiente Manuel Saturio Valencia (18671907), por considerarlo responsable de este crimen que destruyó los principales establecimientos de la ciudad. ${ }^{2}$ En medio de la alarma que significaba ver la destrucción causada por el fuego, Valencia fue torturado y juzgado culpable -en un proceso que duró menos de una semana- y murió fusilado el 7 de mayo. El fusilamiento del "Diablo", como era conocido Valencia, se instaló en la memoria popular proyectándolo como figura de estatura mítica en la que conviven y se resignifican ansiedades, miedos y anhelos colectivos que subyacen a la construcción de la "fragmentada" nación colombiana. ${ }^{3}$ Como constata Olga Arbeláez en un estudio ya clásico, "la versión popular insiste en que Valencia fue acusado de un crimen que no cometió", ya que algunos chocoanos "aseguran que fueron los blancos de la ciudad quienes prendieron el fuego y plantaron la evidencia” en su casa (2004: 20). Trascendiendo cuestiones asociadas a culpabilidad o inocencia, para los habitantes del Chocó Valencia se ha convertido en un símbolo desde el cual reinterpretan su historia para inscribirse en ella como herederos de una genealogía de resistencia y heroísmo. ${ }^{4}$

Sin evitar la referencia histórica, de la que hay escasa evidencia documentada, me interesa detenerme en las coordenadas simbólicas que han alimentado desde la literatura la permanencia y progresiva politización de Saturio Valencia. Sin duda significativo es el delito del que fue acusado, cuya resonancia recupera vestigios de antiguas tradiciones y visiones cosmogónicas. En la cultura occidental, como atestigua el robo de Prometeo y su martirio posterior, la conquista del fuego ha dado lugar a mitos que intentan responder a las interrogantes sobre el origen de la vida y de la civilización. Domesticado en la forma de las brasas que dan un sentido divino al hogar, el fuego refiere metafóricamente al deseo del hombre de imaginarse en control del tiempo y de la muerte.

\footnotetext{
${ }^{2}$ Además de ser líder político, juez de rentas, combatiente de la Guerra de los Mil Días, Valencia fue afamado poeta de cantos satíricos en los que denunciaba la discriminación racial. En Del sentimiento de la poesía popular chocoana (Caicedo, 1973) aparece uno de los pocos poemas de Valencia que se conservan. También Mosquera Rivas incluye el poema "Mariposas del amor", al parecer de autoría de Valencia (2016: 471-2). La ley 1042 de 2006 estableció a Valencia como prócer que "legó su vida a la defensa de los derechos civiles y políticos de los colombianos de ancestría africana". Ver, http://www.suin-juriscol.gov.co/viewDocument.asp?ruta=Leyes/1673027. Sobre la vida y obra de Valencia, ver Gaitán (1995: 1051-3), Leal (2007) y Wade (1997: 144-149).

${ }^{3}$ Alfonso Múnera sostiene que el mito fundacional de la nación neogranadina se enfrentó al obstáculo de la fragmentada geografía que influyó en el desarrollo de grupos culturalmente disímiles y económicamente autónomos, lo que generó una serie de conflictos políticos y sociales (2005).

${ }^{4}$ Valencia vivió en el Chocó, región que según Peter Wade representa a la Colombia "negra" en el imaginario nacional. Según el DANE, para el año 2005 la población total del departamento era de 388.476, habitantes, con una proyección de 476.173 para el 2010; de los censados 82,1\% de la población residente en Chocó se auto reconoce como negro, mulato, afrocolombiano o afrodescendiente (Dane, 2005). Ver también Wade (2006) y (2007).
} 
Sobre estas estructuras de base mítica se superponen, a modo de palimpsesto, los estallidos incendiarios, tan devastadores como deliberados, que han influido en los procesos históricos dando cuenta de irrupciones de descontento a través de las cuales el poder se negocia y la resistencia se espectaculariza. Los ejemplos abundan: el incendio de plantaciones durante los alzamientos de esclavos, la quema de pasaportes como denuncia de las políticas migratorias, las protestas callejeras en que se queman banderas o muñecos que representan a líderes políticos. En forma de estallido insurgente en que esplendor y espanto se confunden, el fuego se constituye en un poderoso símbolo para dar cuenta de las recurrentes "pesadillas de la modernización” (Ortega, 2002: 199) en las que individuos o grupos marginados recuperan visibilidad como actores sociales y como fuerzas desestabilizadoras que reclaman cambios políticos.

Leyendo el incendio en clave simbólica, una de las primeras recuperaciones ficcionales de la figura de Valencia lo presenta como perpetrador de un crimen que pretendía convocar a "los de abajo" para que se opusieran a las múltiples formas de discriminación y opresión racial que enfrentaban los habitantes del Chocó a principios del siglo XX. Me refiero a la novela Las memorias del odio (1953), de Rogerio Velásquez (1908-1965), narrada en primera persona como relato testimonial escrito mientras Valencia esperaba el veredicto del juez. El tono confesional imprime una enorme fuerza a la declaración de que se reconoce como "un sátiro, un monstruo, uno de esos que nacen para castigo de la especie" (1992: 44). El relato de Velásquez se esfuerza por construir a Valencia como símbolo del malestar social provocado por la pobreza, la desprotección frente a los abusos y la invisibilización en que se encontraban las comunidades negras en Colombia. Así lo expresa el narrador:

desde mi nacimiento hasta hoy fui de los de abajo, de los animales de llanura y de montes que luchan como los perros y las fieras para alcanzar un poco de felicidad (1992: 9-10)

$[\ldots]$

con la razón obnubilada, alterado por las enfermedades y el despecho, creí, como mis antecesores, que vaho de fuego cambiaría las cosas. Por esto, envolviendo la bola de trapo empapada en petróleo, reía...reía...

Al salir a quemar deseaba oír crujir las casas, ver despedazados los cimientos, borradas las tribunas. [...] el sollozo de las vírgenes, el olor a cabello y a carne, la pólvora que estalla, la sangre, todo me hubiera dado un poco de alegría, diabólica, sí, pero alegría... (1992: 60)

Velásquez niega la versión popular de que Valencia fue víctima de una conspiración y reconstruye la historia a partir de un acto deliberado de destrucción de la ciudad. ${ }^{5}$ Al convertirse en sujeto de su propia historia, la subjetividad que enuncia las “memorias” reclama para sí y para su comunidad

\footnotetext{
${ }^{5}$ Velásquez, quien fue periodista, narrador y etnógrafo, refiere en la introducción a la primera edición, titulada "Razón de este libro", que durante sus investigaciones encontró la confesión y los documentos del juicio de Valencia. Para enfatizar la veracidad del relato, incluye, a modo de apéndice, la sentencia del juicio y el acta de ejecución.
} 
el protagonismo histórico declarándose heredero de una genealogía heroica. ${ }^{6}$ Más importante aún, Velásquez desmonta los engranajes de la masculinidad heroica en que se fundan los símbolos nacionales enfrentando al lector con un héroe escindido que al sentirse alienado decide establecer a través del incendio un diálogo brutal con el poder.

No es sorprendente, entonces, que Manuel Zapata Olivella (1920-2004), el reconocido novelista afrocolombiano, explore en su novela El fusilamiento del diablo (1986) la fascinante y controvertida figura de Valencia. ${ }^{7}$ Si bien la novela de Velásquez se inscribe como pre-texto, Zapata Olivella resignifica la figura de Valencia proponiendo una exploración de los múltiples factores que intervinieron en los procesos de exclusión, silenciamiento y criminalización de amplios sectores de la población latinoamericana en la segunda mitad del siglo XX ${ }^{8}$ La hibridez discursiva que caracteriza el relato de Zapata Olivella se traslada a la configuración del protagonista cuyas máscaras demoníacas no alcanzan a encubrir la reconfiguración de una masculinidad negra heroica en guerra con el status quo y con quienes ostentan el poder económico y político oprimiendo al pueblo chocoano. ${ }^{9}$ Es justamente el estudio de la configuración de la masculinidad negra heroica lograda por Zapata Olivella en esta novela el eje sobre el que voy a desarrollar mi análisis en las páginas que siguen.

Resulta particularmente significativa la elección del fusilamiento como episodio central de la ficcionalización desde la cual Zapata Olivella estratégicamente politiza la figura histórica prestándole ribetes de héroe revolucionario a tono con los debates que acapararon la atención de intelectuales latinoamericanos en el periodo posterior a la Revolución Cubana (1959). Además, la novela vehiculiza una lúcida denuncia sobre la debilidad de la ley y sobre la criminalización de la rebeldía. Valencia es concebido por Zapata Olivella como un revolucionario, y, por tanto, su fusilamiento se relaciona con su capacidad para liderar grupos armados y con el deseo de ciertos individuos de evitar el levantamiento político de la población negra que se sentía marginalizada y explotada. Así, la reconstrucción de su historia apela a reconfigurar las coordenadas de una genealogía que se funda a partir de la muerte del ancestro ilustre, valeroso y heroico.

\footnotetext{
${ }^{6}$ Dice el narrador "mi memoria se vuelve hacia el pasado. Blancos fueron los que mataron a Luis Escuderos, el pobre peruano que ambicionó ver a los negros gobernándose, dándose sus propias leyes, subiendo en la escala social con su alma, pintoresca, tatuada en leyendas, en cuentos y en imágenes. Dicen que murió como héroe. Su delito fue hacer soñar por un momento a la raza vencida" (1992: 65). Don Nicomedes Conto, José Nicanor Mosquera, Salomón Posso, son otros de los que el narrador reconoce como héroes (1992: 65-67).

${ }^{7}$ Zapata Olivella, quien fue médico, diplomático, antropólogo y folclorista, es uno de los pocos escritores afrocolombianos que ha proyectado la reivindicación racial a nivel internacional. Algunas de sus obras narrativas son: Chambacú, corral de negros (1963), En Chimá nace un santo (1963), Changó, el gran putas (1983). Entre sus ensayos deben destacarse: Las claves mágicas de América (1989), La rebelión de los genes. El mestizaje americano en la sociedad futura (1997) y El árbol brujo de la libertad. Africa en Colombia. Orígenes, transculturación, presencia (2002). Ver Ortiz (2001) y Tillis (2005). Respecto a su recepción crítica, John Maddox (2016) reconoce que "su obra apenas ha comenzado a recibir la atención internacional que merece, como es evidente en el homenaje internacional organizado por Mina Aragón, en 2014, y cuyas memorias aparecen en Un legado intercultural (2016)" (14).

${ }^{8}$ En 1983, Teresa Martínez de Varela (1913-1998) público Mi Cristo negro, novela biográfica en la cual Valencia aparece como víctima del prejuicio racial. Unos años después de la novela de Zapata Olivella, apareció Manuel Saturio (El hombre) (1992), de Miguel Caicedo (1919-1995). En teatro, el Proyecto Teatral Jóvenes Creadores del Chocó presentó en febrero de 2011 la obra Amangualados. El fusilamiento de Manuel Saturio Valencia, de Eugenio Gómez Borrero.

${ }^{9}$ Por hibridez discursiva me refiero a la propuesta de Arbeláez, quien señaló que en El fusilamiento del diablo convergen elementos de la novela histórica, el testimonio y la novela testimonial (2004: 18). Zapata Olivella incorpora documentos históricos y narrativos sobre la vida, el juicio y la condena de Valencia, y también entrevistas que sostuvo con sus descendientes. Ver también, Alzate (2008: 176).
} 


\section{Miradas al heroísmo en América Latina}

Las expresiones políticas del mito heroico en América Latina, y las formas en que se ha estudiado, incluyen una variada gama de actores que van desde el líder militar y revolucionario hasta el bandido, pasando por una galería de estadistas, caudillos, líderes reformadores, activistas, artistas y guerrilleros, cuyo carisma provoca la fidelidad de sus seguidores que arriesgan junto a ellos la vida en la guerra y les rinden admiración hasta después de su muerte. ${ }^{10}$ Ben Fallaw y Samuel Brunk, en su fundamental trabajo Heroes and Hero Cults in Latin America (2006), definen al héroe como "a person to whom remarkable courage, talent, and other noble, even godlike traits are attributed by members of a community and who thus acquires a lasting place of importance in that community's culture" (2006: 1). Utilizando el concepto de carisma propuesto por Max Weber, Brunk y Fallaw proponen un examen de la figura heroica a través de su capacidad para obtener la admiración y el afecto de amplios sectores de la sociedad. Sin duda, la consolidación de un sentimiento de pertenencia a la comunidad imaginada se apoyó en el reconocimiento de ciertos "héroes" bajo cuya sombra monumental se crearon las narrativas nacionales. ${ }^{11}$ Las coordenadas imaginativas, desatendidas por Brunk y Fallaw, nos permiten explorar cómo, al ocupar simbólicamente el espacio sagrado del "héroe", algunos líderes políticos generaron en torno a sí y a su agenda política una red de movilizaciones populares que en algunos casos se opuso y en otros favoreció a las elites en sus proyectos de reorganización nacional.

Sin duda, concebir al héroe implica un juego imaginativo cuyo rol fundamental en la preservación del sentido histórico de la nación enfatiza la necesidad de una estructura jerárquica que oculta, detrás de la monumentalización del "gran hombre", la desigualdad social. ${ }^{12}$ Por su propia naturaleza mítica, el héroe sostiene una red semántica que ampara lo extraordinario bajo la estructura arquetípica permitiéndonos imaginar proezas imposibles. Según lo han estudiado Otto Rank en The Myth of the Birth of the Hero (1909) y Joseph Campbell en The Hero with a Thousand Faces (1949), se trata de la narrativización de vidas ejemplares que constituyen modelos de socialización basados en la integridad de un yo que se fortalece a través del reconocimiento de su pertenencia a una comunidad. Sin embargo, la novela moderna va más allá en su exploración de los alcances y limitaciones de nociones tales como justicia, representatividad y memoria a través de la configuración de héroes que cuestionan el orden establecido, denuncian su ilegitimidad o corrupción y proponen nuevas visiones del entramado social, algunas de ellas utópicas.

\footnotetext{
${ }^{10}$ La preocupación histórica por la figura heroica se produjo en sintonía con la imaginación romántica y las movilizaciones democratizadoras e independentistas, como lo atestigua el trabajo de Thomas Carlyle (1775-1881). En On Heroes, Hero Worship and the Heroic in History (1841) Carlyle argumentó a favor de la concentración de poder en manos del "hombre capaz" ("the Able-man"). En términos de Carlyle, la "divina virtud" de gobernar emana de la naturaleza "superior" del héroe, quien debe ser reconocido como legítimo líder político. Esta teorización resignificó la visión mítica del héroe épico para dar cuenta de las preocupaciones de una época en que los proyectos liberales necesitaban apoyarse en figuras heroicas para promover modelos identitarios que masculinizaron las nociones de progreso, modernidad y blanquitud.

${ }^{11}$ En Imagined Communities, Benedict Anderson sugiere que el proceso de formación nacional se sustenta en lazos identitarios construidos desde la operación de imaginar una historia y cultura común.

${ }^{12}$ En los últimos años ha aparecido una serie de estudios que dan cuenta del renovado interés de la crítica por revisar el impacto y la persistencia de las narraciones heroicas. La fabrique des héros (1999) editado por Pierre Centlivres, Denis Fabre y Françoise Zonabend, Epicidad y heroísmo en la literatura hispanoamericana (2009) editado por Maryse Renaud y Perfiles del heroísmo en la literatura hispánica de entresiglos (XIX-XX) (2013) editado por Luis Álvarez Castro y Denise DuPont, son solo algunos ejemplos de recientes estudios.
} 
Teniendo en cuenta la centralidad de la figura heroica en la configuración y ritualización de los mitos nacionales, considero crucial el estudio de intervenciones elaboradas por autores, pensadores y artistas afrodescendientes que intentaron, como Zapata Olivella, cuestionar, alterar o subvertir estas construcciones. Más aún, en el contexto latinoamericano que se caracteriza por su posición periférica y heterogénea con respecto a los centros de poder de la modernidad, la categoría heroica se manifiesta particularmente productiva por su fluidez y su cercanía a las categorías de "antihéroe", "villano" o "bandido", ya que cuando representa a un grupo minoritario el héroe se ve obligado a operar desde los márgenes y en oposición al orden establecido. ${ }^{13}$

Es así, que, al explorar la construcción heroica de Valencia en El fusilamiento del diablo este ensayo sugiere que Zapata Olivella propuso al cuerpo del hombre negro como símbolo de la promesa revolucionaria latinoamericana. Como modelo de resistencia y lucha en pro de la equidad racial y la justicia social, Valencia se manifiesta como figura de gran poder alegórico. El escritor afrocolombiano muestra su destreza al manipular la figura heroica para que en ella converjan el surgimiento de una conciencia racial fuertemente unida a una conciencia de clase desde la que se funda una genealogía chocoana heroica, al punto que, la faceta "diabólica" de Valencia al ser construida por sus enemigos -esto es: los representantes del poder abusivo de funcionarios del Estado y empresarios- se convierte en una máscara más de las múltiples configuraciones de su heroicidad. A través del uso de la polifonía y la fragmentación, Zapata Olivella incorpora múltiples perspectivas que al dar cuenta del "Diablo" y del criminal enfatizan la lucha de un héroe en búsqueda de concretar para su pueblo la utopía revolucionaria. Hábilmente el autor desplaza a su protagonista por diferentes escenarios, en diferentes épocas y circunstancias en las que el hombre alterna con el niño, el revolucionario con el dandy, el criminal sediento de venganza con el enamorado. Valencia se reviste, así, de una gama de atributos que hacen de él una figura ubicua y poderosa. Además, al desplazarse por diferentes escenarios y desdoblarse en una diversidad de voces, puede narrar en primera persona las múltiples experiencias de opresión que enfrentan los afrochocoanos. Por último, me interesa sugerir que, a través de la utilización retórica del fusilamiento, en tanto espectáculo orquestado desde las instituciones del estado, el autor propone una revisión de los procesos de criminalización a los que se ven expuestos los afrocolombianos, al mismo tiempo que denuncia la fragilidad de la ley y su rol en la constitución y mantenimiento de estructuras de privilegio y desigualdad.

\section{El fusilamiento del diablo y la masculinidad heroica afrochocoana}

Desde los augurios de la tía ciega que le decía cuando niño que debía aprender a leer para no ser "un ignorante que persiga la policía" (1986: 9), hasta su llegada al pueblo capturado y maniatado, Valencia es construido por Zapata Olivella siguiendo las coordenadas del líder popular que arriesga la vida por enfrentarse al poder establecido. Sin embargo, lo que lo distingue es su apelación a una identidad racial que se manifiesta en guerra con el mundo de los "blancos" que son representados como perpetradores de la desigualdad social. Así, por su carisma y capacidad de convocatoria entre los afrochocoanos, el rebelde se constituye en un peligro para los individuos en el poder.

\footnotetext{
${ }^{13}$ A este respecto, ver el estudio de Juan Pablo Dabove (2007).
} 
Valencia lo enuncia del siguiente modo: "[e]sos mismos policías que te llevan preso se sienten defraudados. Aunque los uniformaron y les pusieron fusiles en las manos tenían la ilusión de que tú pudieras humillar a los blancos y los hicieras libres, amos del pueblo, de las minas, de los ríos y de tantas cosas que les han quitado" (1986: 14). A través de los múltiples desplazamientos de la voz narrativa la novela se constituye en el vocero de habitantes del Chocó que se sienten marginados y olvidados por las instituciones gubernamentales. Dice uno de los narradores: "[u]stedes deben saber que los nacidos en este pueblo somos rebeldes por nacimiento" (1986: 23). Valencia cumple, así, con su designio de héroe, en tanto provoca una identificación entre el individuo y el colectivo social. También se naturaliza la rebeldía como elemento constitutivo del "ser" chocoano.

Valencia es, además, una subjetividad en constante peligro cuya raigambre mítica se construye a partir de situarlo en posiciones liminares. ${ }^{14} \mathrm{Su}$ nacimiento, por ejemplo, se configura enmarcado en vaticinios que anuncian su lucha denodada contra los obstáculos y la persecución que deberá eludir. Así se anuncia su alumbramiento:

Alguna traba le han puesto para que el hijo no salga derecho. Hasta la comadrona se desconcierta al comprobar que sus codos apoyados sobre la matriz no consiguen expulsarlo. Abandona el cuarto y en la cocina, rodeada de viejas parinderas, desahoga sus conjeturas: - No cabe duda de que el blanco Valencia le está velando un "santo en cruz" para ahogar su propio hijo antes de que nazca, todo porque lo tuvo con una negra. [...]

Las ancianas más viejas opinan y dan consejos. Advierten el peligro que el padre ausente no entierre la placenta si nace el hijo. Sin ataduras que lo amarren a la tierra y a la ley, sería un vagabundo desbordado de crímenes. (1986: 10-11)

Narrado en clave mítica, su nacimiento refiere a la búsqueda del origen a través de una paternidad en disputa que enfatiza la pérdida o ruptura del linaje debido a la conflictiva relación entre grupos que se identifican como pertenecientes a razas antagónicas. ${ }^{15}$ Además de sumirlo en un espacio marcado por la imaginación popular, Zapata Olivella recurre a lo que denominó "realismo mítico" que sostiene la analogía creada entre los opuestos muerte / vida y blanco / negro. A través del tono profético, este fragmento potencia la imagen que en la novela precede al nacimiento: la captura de Valencia por la policía.

Silvia Valero acertadamente ha señalado que, con la publicación de Changó, el gran putas (1983) Zapata Olivella inauguró una novelística que imagina el origen mítico-histórico africano como signo de pertenencia a la diáspora africana en América (2015b: 90). Sin duda, Changó, el gran putas es la más representativa ficcionalización de la escritura afrodiásporica latinoamericana. ${ }^{16} \operatorname{Sin}$

\footnotetext{
${ }^{14}$ Raymond L. Williams y José Manuel Medrano señalan en su estudio de la novela moderna colombiana la estatura mítica del personaje de Saturio Valencia construido por Zapata Olivella (2018: 165).

${ }^{15}$ En referencia al uso de estructuras arquetípicas en la obra de Zapata Olivella, consular el estudio de Aida Heredia (1987).

${ }^{16}$ Ver Mose, (1988); Tillis (2006) y Garavito (1997).
} 
embargo, El fusilamiento del diablo también incluye la representación de sujetos cuya pertenencia a una comunidad se establece a través de su reconocimiento de un saber ancestral. Más aún, en el caso de Valencia su concientización racial y política se produce al reconocerse heredero de un linaje que ha resistido la opresión por varias generaciones. Es a través de su conexión con su ancestro que el héroe se reconoce como tal. ${ }^{17} \mathrm{La}$ escena se da en una mina en la que Valencia y sus seguidores intentaban ocultarse de sus perseguidores y encuentran un cementerio de esclavos. Así le habla el ancestro:

"Soy tu abuelo. Tengo doscientos años de estar aqui en la mina. Es mejor que te quedes quieto. Te despellejarán la espalda. Perderás las uñas de tanto arañar la tierra. La fatiga mata pero no tanto como el hambre". No tenía ojos. Sus cuencas rellenas de lagañas devoradas por las moscas. ¿Su abuelo? Comparaba sus edades, sus rostros, su dolor, idénticos ¡Doscientos años! La edad real de su cautiverio. [...] Sentía necesidad de erguirse porque él no era un esclavo. "Los Carabalí no conocieron nunca la esclavitud". [...] Ahora comprendía. [...] Reclamaría la libertad. (énfasis en el original, 1986: 177-178).

El autor hábilmente hace converger en la mina varias temporalidades - la del tráfico y explotación esclavista, la niñez de Valencia y el presente de la narración - enfatizando el contraste establecido entre la continuidad de las estructuras de opresión y la ruptura que significa el momento de anagnórisis del héroe. Así se lo dice a sus seguidores: "Hemos dormido en un cementerio de esclavos. Miren aquí están los esqueletos amarrados todavía con argollas” (1986: 179). Luego aclara el narrador que los hombres se "pusieron a cavar. La cadena oxidada se alargaba cada vez más con los huesos rotos, unos detrás de otros, hundidos en lo más profundo de la tierra" (1986: 179). La acción de "cavar" unifica simbólicamente la minería, actividad histórica del territorio chocoano, con el intento de restitución del legado afrodescendiente. Al decir el narrador que los hombres "habían perdido la memoria" porque tenían "un pasado sin nombre, perdido en el relato" (1986: 179), Zapata Olivella incluye en el proceso de recuperación al lector y alerta acerca de la necesidad de una literatura comprometida con la recuperación simbólica del pasado afrodescendiente en la región. ${ }^{18}$

A través del acto de recuperar los huesos de sus ancestros y de "desenterrar" la historia de los afrodescendientes en el territorio chocoano, el autor hace confluir pasado y presente apelando a la identidad minera del Chocó. Según Yijhan Renteria Salazar, la minería es "una actividad sin la cual el chocoano no podría reconocerse como tal en ningún momento de su historia” (2013: 51).

\footnotetext{
${ }^{17}$ Según Arbeláez, la filosofía que permea el universo de los personajes afrochocoanos en la novela es la del muntú (2004: 24). Zapata Olivella lo explica en El árbol brujo de la libertad (2002) como el locus de la sabiduría de "los Antepasados y Abuelos, memoria viva de los ancestros, quienes nos relataran como el Muntu Africano, padre de la danza y la palabra, pudo atrapar el fuego; sembrar la semilla allí donde quiso cosechar los frutos; convertir la caverna en templo para sus dioses y cacerías mágicas" (23). El árbol brujo de la libertad enfatiza la necesidad de incorporar una práctica intelectual que se desplace entre saberes, mitología e historia (Aldana, 2006: 49). La inclusión de historias orales y de elementos mágico-religiosos interrumpe la hegemonía del discurso oficial instaurando lo que el investigador venezolano Jesús García ha llamado afroepistemología. Siguiendo a Valero, la afroepistemología requiere una revisión histórica de la diáspora africana "no solo en cuanto recuperación y resignificación de sus contenidos, sino como plataforma desde donde reconstruir la identidad de una comunidad concebida transhistóricamente" (2015: 532).

${ }^{18}$ Laurence Prescott sostiene que la negritud, el mestizaje y la identidad fueron las preocupaciones constantes de Zapata Olivella, quien entendía la literatura como arma de combate y de autodescubrimiento (2016: 104).
} 
La mina ha funcionado como espacio simbólico por excelencia para negociar y definir la identidad colectiva de los pobladores del Chocó. En la novela de Zapata Olivella, la mina se muestra arraigada a los discursos que construyen el "ser" chocoano constituyéndose también en el espacio del autodescubrimiento y de la reflexión política. Desde la condición atemporal del relato mítico, el autor hace confluir el pasado de esclavitud con los sucesos que preocupaban a los chocoanos en la década de 1980, momento de escritura y publicación de la novela. Según lo informa la revista Síntesis económica en un artículo titulado "El renacer de Mineros del Chocó” (1984), la Compañía Minera Chocó Pacífico perteneciente al grupo South American Gold and Platinum Co. había vendido sus acciones al Sindicato de la Chocó Pacífico en 1977, pero en menos de cinco años esta empresa se había enfrentado a una grave crisis, por lo que se requirió la intervención del gobierno. Durante la presidencia de Belisario Betancur Cuartas (1982-1986) se hicieron estudios de factibilidad de la compañía y se decidió crear un fondo económico destinado a solventar la empresa Mineros del Chocó (1984: 4-5). Es así, que, la novela se arraiga fuertemente en su contemporaneidad y desde su presente de enunciación reclama atención sobre la persistencia de estructuras económicas y culturales que reproducen las formas de dominación del pasado esclavista. La perspectiva que incorpora la novela revindica el valor del trabajo y de la producción minera en manos de los trabajadores intentando unificar la identidad regional con el proyecto nacional al oponerlo a los intereses extranjeros de explotación indiscriminada de los recursos humanos y naturales.

Además de constituir la principal característica mediante la cual el pueblo chocoano se define, la producción minera es también la que más se ve amenazada por la acción estatal que ha puesto la explotación de minerales en manos de empresas multinacionales amenazando la sobrevivencia de la minería tradicional (Renteria Salazar, 2013: 52). Zapata Olivella, quien convivió con los obreros de la compañía Chocó Pacífico, denuncia en la novela que la minería extranjera a pesar de su promesa de modernidad y progreso para la región ha prolongado las terribles condiciones de explotación creadas durante la esclavitud destruyendo a su paso la identidad comunitaria. ${ }^{19} \mathrm{La}$ explotación económica se narra utilizando elementos de gran visualidad tendientes a despertar la empatía del lector, sobre todo porque se representa a través de la experiencia de un niño. Zapata Olivella ubica a Valencia trabajando para la compañía minera, como muchos chocoanos, durante su niñez. Una vez más se encuentran en la novela varias generaciones, ya que es un viejo tuberculoso, que se propone como su "tío" y protector, quien le advierte al joven Valencia:

has vendido tu vida. Eso quiere decir que dejas de ser dueño de tus brazos, de tus pulmones, de tu descanso. La mina revienta. Un día serás saliva de tuberculoso, sombra de ciego, oído de sordo. Su tos llena de huecos era un relato más dramático que los escupitajos de sangre que escupía. (énfasis en el original, 1986: 140-41)

El cuerpo destruido por las terribles condiciones de explotación laboral refiere simbólicamente al deterioro del cuerpo político de la nación ante la invasión de las empresas multinacionales. A través

\footnotetext{
${ }^{19}$ Zapata Olivella cuenta en La rebelión de los genes que "[e]xasperado ante los enfermos que llegaban al hospital y salían de él sin el diagnóstico real de la enfermedad que los abatía -la miseria social-, decidí descubrirla por mí mismo conviviendo con los obreros de la compañía norteamericana Chocó Pacífico, tema de mi última novela El fusilamiento del diablo" (1997: 23).
} 
de su acción redentora, es el héroe en quien recae la responsabilidad de reparar el daño infringido a la integridad y soberanía nacional.

En la novela, el encuentro del cementerio de esclavos activa la concientización colectiva ya que la esclavización y la explotación extranjera del suelo chocoano funcionan como experiencias unificadoras. A partir del reconocimiento de su pasado común los hombres comienzan a concebirse políticamente como cuerpo rebelde y es Valencia quien lidera la acción. Así les dice a sus seguidores:

- Desde este punto en adelante nos constituimos en bando propio. [...] formemos nuestro propio partido: alzados contra quienes hasta ahora nos han obligado a pelear unos contra otros para mejor esclavizarnos. [...] pues no vamos a ser toda la vida esclavos, ayer de los señoritos caretejos y ahora de los místeres que quieren robarnos las minas de nuestros abuelos. Ya basta. Ya no más. Se acabó la guerra de los negros bobos. [...] no más negros encorvados frente al puñado de jipatos intendentes, administradores, amos, tesoreros y jueces. (1986: 179)

El fragmento muestra el proceso de autoafirmación identitaria que se inicia a partir del encuentro con el ancestro y que propicia el establecimiento de lazos fraternos entre la comunidad. A este respecto, El fusilamiento del diablo cumple con las características establecidas por Valero como constitutivas de la literatura afrolatinoamericana contemporánea (2015a:13). Creando un lenguaje que permite reconstruir y dar sentido a la experiencia afrodiaspórica, Zapata Olivella ubica a la masculinidad negra heroica en el centro del relato como sujeto de su devenir histórico y como propulsor de cambios políticos.

Al ganar conciencia política y agencia sobre su propio destino, el cuerpo amenazado del hombre negro se convierte en cuerpo amenazante que despierta el miedo de los individuos que ejercen el poder. La utilización del tropo del $d a n d y$ asociado a lo satánico y perturbador, ya que Valencia es un seductor que enamora entre otras a Eustaquia - una joven blanca perteneciente a una familia de la clase alta - revela la ambigüedad de la construcción de la masculinidad heroica negra. Así lo cuenta Valencia: "piensan que puedo desaparecer ante sus propios ojos y convertirme en fuego que les chamusque la piel. Sus mujeres arrojan agua bendita a mi paso y cierran las ventanas. Jamás han visto al "Diablo" en persona. Buscan los cuernos en tu frente, el rabo peludo entre tus piernas y las pezuñas de oro que dejen huellas de fuego" (énfasis en el original, 1986: 15). Además de la demonización que da cuenta del miedo que despierta la corporalidad del hombre negro, como líder popular, Valencia es el "Diablo" para las autoridades estatales y los representantes de la compañía Chocó Pacífico. Por ejemplo, el juez encargado de condenar a Valencia y su esposa no pueden dormir y creen ver al "Diablo" acechándolos en todas partes. Dice el narrador:

Un sudor pegajoso le empapaba el cuello [...]

Y ahí estaba la visión blanca. De repente sintió unas ganas incontenibles de orinar.

- Mija, veo un fantasma! (1986: 62) 
Atemorizada se hincó de rodillas y dentro del toldo se puso a rezar, la plegaria orientada hacia los lados del altarcito.

- Esos son los hechizos del "Diablo”. [...]

Su miedo se debía a la venganza anunciada de los negros. (énfasis en el original, 1986: 63)

El fragmento es elocuente en la identificación del héroe con la amenaza de alzamiento popular. De este modo, Zapata Olivella estratégicamente hace confluir la criminalización de la rebeldía con la presencia de un héroe con el cual la población negra se identifica al punto de despertar el terror en las autoridades estatales. Así lo expresa otro personaje: "no era cuestión de dar muerte al bandolero, sino de instaurar el principio de que todo aquel que se alzara contra la autoridad quedaba ipso facto sentenciado a muerte" (1986: 16). La captura y ejecución del "Diablo" deshumaniza al hombre negro y lo coloca en la posición de objeto usado como caso ejemplarizante para evitar futuras revueltas que amenacen el orden establecido.

El autor crea un héroe antiimperialista de estatura mítica que se ubica en múltiples contextos de lucha. En compañía de otros que como él rechazan el sistema de explotación económica y exclusión social, Valencia se desplaza por la región atacando campamentos mineros y creando su propio grupo de guerrilleros que se alzan en armas después de la Guerra de los Mil Días (1899-1902). Su pequeño ejército de guerrilleros atacaba pueblos mineros y "a su paso huían los gringos porque su puño jamás tembló para hendirles el cuello" (1986: 180), mientras aumentaba el número de sus seguidores. Sietecueros, Mojarra, Diostedé, son algunos de los compañeros de armas de Valencia que, en palabras del narrador, actuaban como "personajes míticos, zapadores de sus propias vidas" aunque "ignoraban que eran los héroes de las más extraordinarias historias" (1986: 61). Convertidos en "libres y libertadores" (1986: 180), Valencia y sus hombres "abrían las bodegas y repartían los bultos de carne ya podrida de tanto esperar una boca hambrienta. Había ancianos que comían por vez primera hasta reventar y niños indigestos con solo probarla. [...] Prendían fuego a cárceles y libertaban a gente cuyo único delito era estar hambreados" (1986: 181). Desde la perspectiva del narrador, no se trata de bandoleros o bandidos sino de rebeldes que guiados por firmes ideales de justicia intentan restituir la dignidad a una comunidad de trabajadores que han sido criminalizados y que carecen de lo necesario para su sobrevivencia.

La figura del rebelde admite inagotables versiones. Así, el personaje de Valencia se desdobla en múltiples agentes que enfrentando a los representantes del Estado o de las multinacionales defienden su derecho al trabajo y a la tierra. Aunque sean ciertos hombres quienes tomen la iniciativa y lideren la rebelión, la historia que le interesa destacar al autor afrocolombiano es la resistencia organizada del pueblo. ${ }^{20} \mathrm{La}$ defensa del cementerio, por ejemplo, asume valor político porque genera

${ }^{20}$ Thomas Kooreman (1987) plantea un relevante recorrido por la tematización de la protesta social en la narrativa de Zapata Olivella. Las entrevistas a Zapata Olivella revelan la centralidad de su conceptualización de "las luchas de los negros tratando de afirmar su presencia" en el proceso histórico del continente (Captain-Hidalgo, 1985: 28). Ver también, Krakusin (2001) y Harris (1991). 
la unión de los mineros que liderados por el abogado afrochocoano Marino Quetecú, defensor de Valencia, enfrentan a los obreros que intentan excavar la tierra en que descansan sus muertos. El sentido de comunidad se consolida a través de la protesta por preservar el espacio sagrado del cementerio y así lo expresa el narrador:

El doctor Quetecú no se resignaba a presenciar impasible aquel atropello y reunió a los vecinos dispuestos a impedir el desalojo de sus muertos de las viejas sepulturas. (1986: 168)

$[\ldots]$

Las mujeres de rodillas cantaban alabados, amparando con sus brazos a sus pequeños. Los hombres de pie acompañaban el coro. El abogado, siguiendo una tradición que le venía de abuelos rezanderos, se sumaba a aquella plegaria. (1986: 169)

$[\ldots]$

El abogado elevó más el canto convencido de que con aquella resistencia pasiva también se defendía el derecho tradicional de gentes. (1986: 170)

La masculinidad negra heroica se concibe a partir de múltiples formas de rebeldía que van desde el modelo de "resistencia pasiva" que encarna el abogado hasta el alzamiento armado del pequeño ejército liderado por Valencia. El héroe, en tanto categoría del discurso, permite la inclusión de subjetividades diversas potenciando la capacidad inclusiva de la comunidad imaginada por Zapata Olivella.

La mitificación del rebelde se apoya en una construcción que espectaculariza el despliegue del cuerpo del hombre negro. Como evento que convierte a la muerte en acto público de castigo para quien es considerado criminal peligroso, el fusilamiento coloca al cuerpo del héroe como espacio de resistencia al aparato represor del Estado. Así lo describe el narrador: "el cadáver se recalentaba aunque los proyectiles le habían sembrado troneras en la cara. Un ojo, inmensamente abierto, persistía vivo y agitado. El comandante ordenó a un policía que se lo cerrara, pero el párpado volvía a recogerse" (1986: 205). La tenacidad de la mirada de Valencia que, a pesar de haber sido ejecutado continúa demandando atención, adquiere un intenso valor simbólico. Sin embargo, son las palabras de su tía ciega las que logran imprimirle mayor dramatismo a la escena. Dice la mujer:

Déjame que recoja tus dientes dispersos y los coloque nuevamente en el horizonte blanco que reflejaba la luz cada vez que sonreías. Los labios delgados y redondos hechos a propósito para que silbaran las palabras. Sobre ellos quedan pedazos de esos bigotes retorcidos que te dieron la apariencia de tigre en donde todos creían ver el rostro del diablo. Todavía en tus barbas largas por los muchos días que anduviste perdido en la selva [...] puedo contar los orificios, catorce, que perforaron tu cara. [...] Ya en el fondo de la sepultura te quedaste quieto [...] Desde entonces andas alzado en armas en la mente de negros y mulatos capitaneando la tropa de tus guerrilleros. (1986: 12-13) 
Agredido y disperso por la acción de las balas, el cuerpo de Valencia ingresa a la narración a través de la amorosa enunciación de su tía que intenta reconstruir con sus palabras la integridad perdida. La narración del fusilamiento coloca al cuerpo del héroe en el centro de la historia latinoamericana en diálogo con figuras de proyección internacional. ${ }^{21}$ Zapata Olivella, quien asumió una posición política de izquierda, otorga a su héroe características que recuerdan a la figura de Ernesto "Che" Guevara (1928-1967), quien fue capturado y fusilado en la selva boliviana. ${ }^{22}$ Las fotos del cuerpo sin vida de Guevara tomadas por Freddy Alborta (1932-2005) para documentar una muerte en la que muchos no creían, circularon ampliamente provocando indignación por el maltrato del cadáver del líder revolucionario. ${ }^{23}$ La narrativización del cuerpo masacrado de Valencia, que resiste al fusilamiento y obliga al comandante a darle un último tiro en la cabeza, del mismo modo que la fotografía de Alborta, opera como recordatorio de la inmortalidad de los ideales revolucionarios. El cuerpo del héroe negro se concibe, así, como espacio en el que se inscribe la violencia represiva del Estado, pero también como poderoso símbolo de la resistencia contra la opresión imperialista.

\section{El heroísmo negro y el proyecto anticolonialista de Zapata Olivella}

La heroización de Valencia está ligada, sin duda, al proyecto anticolonialista de Zapata Olivella que lee en la historia de la esclavitud una constante lucha del negro por liberarse. Por ejemplo, en Las claves mágicas de América (1998) defiende que "puede afirmarse en forma categórica que ningún otro pueblo en la historia de la humanidad ha estado sometido a una violencia tan expoliadora, masiva y por tantos siglos, y que a la par haya respondido con mayor creatividad a la opresión" (1989: 79). En ese mismo texto defiende que:

Las ideas humanistas y religiosas de los siglos que siguieron al descubrimiento de América se enfrascaron en torno a las libertades y a la naturaleza divina del hombre, mientras los traficantes de esclavos y colonialistas, más prácticos, incrementaban sus ganancias aprovechándose de la capacidad creadora del esclavo. La negación teórica de sus potencias espirituales buscaba el encubrimiento de su triple explotación de clase, raza y cultura. (1998: 77)

Zapata Olivella no solo muestra que la raza ha sido desde la conquista un mecanismo crucial de dominación (Múnera, 2010: 14), sino que también propone que la capacidad creativa de los negros es el pilar de su resistencia. ${ }^{24}$ El racismo, en tanto manifestación de la colonialidad del poder, no es solamente un campo de conflicto (Quijano, $2000: 193$ ), sino que también, es el origen de la

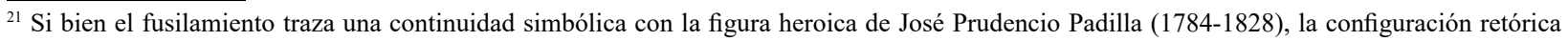
ofrecida en la novela revela, a mi entender, un interés por retratarlo integrado a los debates políticos de los años setenta y ochenta del siglo XX, en el que los escritores asumieron desde su plataforma de hombres públicos posturas comprometidas con diversos movimientos revolucionarios. Ver Franco (1977) y Rama (2005: 164-196).

${ }^{22} \mathrm{Al}$ respecto, George Palacios sostiene que la "filiación con las ideas socialistas y el espíritu de lucha del Partido Comunista facilitan a Zapata Olivella una gramática y vocabularios apropiados en su contexto y momento histórico para acometer la crítica mordaz desde su producción intelectual general y sus obras literarias en particular" (2018: 130). Ver también, Mina Aragón (2016a: 25).

${ }^{23} \mathrm{~A} 1$ respecto es relevante al análisis propuesto por Jean Franco, quien considera al Che como figura icónica en torno a cuyo protagonismo se han tejido una serie de producciones culturales desde la década de los noventa (2002). Ver también, Varas (2014) y Cristoffanini (2014).

${ }^{24}$ Haciéndose eco de la postura de Zapata Olivella, el poeta afrodominicano Blas Jiménez sostiene que "al controlar nuestra definición de cultura, la clase dominante controla nuestra auto-definición y la manera misma de comunicarnos" (2002: 4).
} 
colonización cultural. En la conceptualización propuesta por el escritor colombiano, la recuperación del legado africano es crucial como elemento de reconocimiento y concientización racial, pero lo es más aún como defensa de la cultura nacional frente al imperialismo.

Como señala Alfonso Múnera, Zapata Olivella desarrolló "de manera consistente, sus reflexiones sobre el colonialismo cultural, sobre el racismo y la discriminación, sobre la cultura de los analfabetos y semianalfabetos y sobre el nacionalismo literario", siendo su "corpus teórico de los más audaces y avanzados de la nación en los años sesenta y setenta del pasado siglo" (2010: 15). Si bien desde los años cuarenta el escritor se había vinculado con teóricos y activistas de la negritud, fue en la década de los setenta cuando articuló las bases teóricas del pensamiento afrocaribeño colocando la creatividad social del negro en el centro de la historia cultural latinoamericana. ${ }^{25}$ Por entonces, presentó la conferencia “Opresión y explotación del africano en la colonización de América Latina” (1976) en el XLII Congreso Internacional de Americanistas (Camacho Buitrago, 2015: 37). Al año siguiente organizó a través del Centro de Estudios Afrocolombianos y la Fundación de Investigaciones Folklóricas el primer Congreso de Cultura Negra de las Américas, realizado en Santiago de Cali, en el que reunió por primera vez en América Latina a renombrados intelectuales, científicos, académicos, investigadores, militantes y artistas internacionales. ${ }^{26}$ Según el estudio de Valero, este Primer Congreso fue de crucial importancia para estimular la reflexión "sobre la historia y el presente de los descendientes de africanos y sus contribuciones en la construcción de las Américas en materia cultural y social" (2020: 15) y para estimular la concientización política y la organización en procura de cambios sociales. La revista Letras Nacionales (1965-1985) se postuló durante veinte años como una valiosa plataforma desde la cual el escritor denunció el colonialismo como "elemento coercitivo de la creación literaria propiamente colombiana" (Camacho Buitrago, 2015: 99). Como activista, pensador y creador, Zapata Olivella desarrolló una postura crítica frente al colonialismo como factor que impedía la integración de la comunidad nacional colombiana y promovió, tanto en su obra de ficción como ensayística, la dignificación del legado africano en América Latina. Dentro de este proyecto, la heroización de la subjetividad negra funcionó como recordatorio del valioso aporte hecho por los afrodescendientes a la historia colectiva concibiéndolos como luchadores incansables en búsqueda de justicia y equidad social y convirtiéndolos en modelos de una sociedad diversa e inclusiva.

Al situarse en una tradición intelectual caribeña y africana, la obra de Zapata Olivella se constituyó en precursora de discursos que desde los años sesenta alteraron el mapa ideológico internacional combatiendo la discriminación racial. Dina Camacho Buitrago ha señalado acertadamente que el pensamiento crítico afrocolombiano adquirió forma gracias al sistemático trabajo de Zapata Olivella que "nutrió su pensamiento en el diálogo con el movimiento de la negritud, la crítica de los modelos de explotación colonialista, la reivindicación de los derechos civiles de los negros y

\footnotetext{
${ }^{25}$ Ver, Henao Restrepo (2010) y (2011) y Tillis (2005).

${ }^{26}$ A este respecto, es imprescindible consultar el estudio de Valero, “Los negros se toman la palabra”. Primer Congreso de la Cultura Negra de las Américas: debates al interior de las comisiones y plenarias. (2020). Ver también, Lima Santos (2014).
} 
las luchas de liberación nacional de los países africanos y caribeños" (2015: 113). Sin embargo, el escritor llevó su prédica mucho más allá al concebir la epopeya revolucionaria latinoamericana a partir de la resistencia del negro. En El fusilamiento del diablo el heroísmo se muestra como categoría retórica de gran poder no solo para defender el valor histórico del líder rebelde, sino que al incluir a una multitud de actores también propone la idea de una comunidad en constante enfrentamiento con autoridades del Estado y con representantes de las multinacionales. Valencia se propone, así, como símbolo de la capacidad creativa de la lucha de los afrodescendientes en un momento significativo para América Latina que enfrentaba el avance colonizador de Estados Unidos. A partir de la construcción de la masculinidad negra heroica, Zapata Olivella concibe un proyecto político de dignificación de las comunidades afrodescendientes que revela el potencial insurgente y contestatario de América Latina.

La novela asume un tono de orgullo racial que se expresa en sus personajes, en las tradiciones religiosas, en los bailes y música, así como también en las prácticas cotidianas desde las que denuncian su capacidad de resistencia tanto política como cultural. Ante la criminalización del negro que es convertido en delincuente desde su nacimiento, el fuego se incorpora a la red simbólica desde la cual la novela resignifica el legado heroico de las comunidades negras de América Latina. Así, el desenlace de la novela coloca al lector ante el escape de Valencia, el Diablo, que deja en llamas su sepultura. Así lo dice el narrador:

Los policías se apostaron lo más distante del cementerio. Les corría el terror al verse obligados a custodiar a un muerto a quien vigilaron en vida. Ni siquiera el humo de los cigarrillos conseguía entibiar aquella noche, más fría para ellos que para el sepultado.

Los niños a través de la cerca del cementerio pudieron ver el prodigio esperado.

- ¡Miren! ¡Arde su sepultura!

Los policías apuntaron hacia la llama, los dedos trabados en el gatillo. Les sería imposible fusilar dos veces al “Diablo”. (énfasis en el original, 1986: 209)

Al recuperar el fondo universal de lo trágico, Zapata Olivella hábilmente construye un héroe que se enfrenta valerosamente a un destino que le había sido trazado por los opresores del pueblo afrochocoano: el trabajo en la mina, la enfermedad y el hambre. Sin duda, la creación ficcional de Valencia propuesta por Zapata Olivella es un relato diferente, interferido por la imaginación popular desde la cual la historia de Valencia se convirtió en leyenda y en símbolo de esperanza. A través de la simbología del fuego, el escritor incorpora el legado occidental y la imaginación popular negra, para referir a una masculinidad heroica rebelde de raigambre mítica que se define por su capacidad contestataria y por su voluntad de combate a toda forma de opresión. Además de incorporar al relato la leyenda del "Diablo" como agente de indisciplina y desobediencia, Zapata Olivella alimenta la agencia interpretativa al crear una narración que se mantiene abierta a la interpretación imaginativa. 


\section{A modo de reflexión final}

Arbeláez sostiene acertadamente que "uno de los muchos aportes de Manuel Zapata Olivella en su larga vida de escritor y de intelectual comprometido, es el de haber empezado a llenar el vacío e invisibilidad histórica de los descendientes africanos del nuevo mundo al transformar [ciertos] relatos orales, recopilados a través de su vida y sus innumerables viajes, en texto escrito, con el propósito de difundirlos" (2004: 17). Por su parte, Camacho Buitrago señala que hasta la aparición de Zapata Olivella en el escenario cultural no existía un "campo intelectual afrocolombiano" (2015: 112). Maddox nos recuerda la fuerza precursora del pensamiento afrodiaspórico de Zapata Olivella que se adelantó a la teorización de Paul Gilroy proponiendo una perspectiva transnacional a la experiencia de la diáspora africana (2016). Teniendo como referencia el aporte de estos estudios, este ensayo se concibe como una invitación a releer la obra de Zapata Olivella desde la centralidad de la masculinidad negra heroica, categoría que unifica su concepción de la historia y del legado de los afrodescendientes en América. Resulta elocuente que el escritor afrocolombiano decida reinscribir en la imaginación popular el valor político de la heroicidad negra en un periodo caracterizado por la visibilización de expresiones reivindicativas de movimientos negros en el continente (Agudelo, 2015: 499) y por la gran epopeya heroica de la literatura: el Boom de la narrativa latinoamericana. ${ }^{27}$ La categoría heroica se configura, así, no solo como espacio de contienda, en que imaginación e historia confluyen para crear nuevas formas de entender los lazos comunitarios y la fraternidad nacional, sino también de dignificación para el hombre negro. $E l$ fusilamiento del diablo no intenta, a mi entender, recuperar la figura histórica del "último fusilado de Colombia" sino de incorporarlo como pieza clave para examinar las múltiples experiencias de los "condenados de la tierra" que vieron en él un símbolo de rebeldía y esperanza. La narración de Zapata Olivella traza un recorrido en el que el amenazado cuerpo del hombre negro al convertirse en sujeto enunciador de hazañas y dueño de su historia asume su poder de despertar el miedo en los opresores y de estimular la movilización popular. Sin embargo, al emanar de espacios enunciativos marcados por procesos de marginación, la categoría heroica se carga de las ambigüedades y ambivalencias propias de la condición colonial y periférica de la modernidad latinoamericana. Es así que el héroe se enmascara en la figura del "Diablo" para revindicar su potencial de rebeldía y disidencia política.

\section{BIBLIOGRAFÍA}

Agudelo, C. (2015). Las encrucijadas del reconocimiento multicultural. Los afrodescendientes en América Latina y el Caribe. En: S. Valero y A. Campos García (Eds.) Identidades políticas en tiempos de afrodescendencia: auto-identificación, ancestralidad, visibilidad y derechos humanos (pp. 497-530). Buenos Aires: Corregidor.

\section{Alzate, S. L. (2008). La evolución literaria de Manuel Zapata Olivella: testimonio, autobiografía y novela. Tesis Doctoral, University of Cincinnati.}

\footnotetext{
${ }^{27}$ A mediados de los años sesenta cuando aparecen las publicaciones más célebres del movimiento conocido como el Boom de la narrativa latinoamericana, Zapata Olivella fundaba Letras Nacionales dándole visibilidad al legado cultural de las poblaciones negras. A inicios de la década de los setenta, José María Arguedas (1911-1969) propuso que la literatura era un sacerdocio y ubicó al escritor en el centro de su comunidad a través de adjudicarle trazas de heroicidad a la labor intelectual, ver Rama (2004: 195).
} 
Aldana, L. (2006). Entre mito e historia: hacia una estética fanoniana de la resistencia en El árbol brujo de la libertad de Manuel Zapata Olivella. Afro-Hispanic Review, 25(1), 39-53.

Álvarez Castro, L. y DuPont, D. (Eds.) (2013). Perfiles del heroísmo en la literatura hispánica de entresiglos $(X I X-X X)$. Valladolid: Verdelís.

Anderson, B. (1983). Imagined Communities: Reflections on the Origin and Spread of Nationalism. London: Verso.

Arbeláez, O. (2004). El fusilamiento del diablo de Manuel Zapata Olivella: Historia, novela histórica, testimonio y/o mito. Afro-Hispanic Review, 23(1), 17-27.

Brunk, S., y Fallaw, B. (Eds.). (2006). Heroes and Hero Cults in Latin America. Austin: University of Texas Press.

Caicedo, M. (1973). Del sentimiento en la poesía popular choacana. Medellín: Tip. Italiana.

Caicedo, M. (1992). Manuel Saturio (el Hombre). Medellín: Editorial Lealon.

Camacho Buitrago, D. (2015). Manuel Zapata Olivella, Letras Nacionales y la emergencia de un "relato negro" en el campo intelectual colombiano. Meridional. Revista Chilena de Estudios Latinoamericanos, (4), 97-114.

Campbell, J. (2008). The Hero with a Thousand Faces. Novato, Ca.: New World Library.

Captain-Hildago, Y. (1985). Conversación con el doctor Manuel Zapata Olivella, Bogotá, 1980; 1983. Afro-Hispanic Review 4(1), 26-32.

Carlyle, T. (1846). On Heroes, Hero-worship, and the Heroic in History. New York, Wiley and Putnman.

Centlivres, P., Fabre, D., y Zonabend, F. (Eds.). (1998). La fabrique des héros. Paris: Éditions de la Maison des Sciences de l'Homme.

Cristoffanini, P. R. (2014). Che Guevara: Las significaciones de un ícono global. Sociedad y discurso, $A A U,(26), 1-23$.

Dabove, J. (2007). Nightmares of the Lettered City: Banditry and Literature in Latin America, 1986-1929. Pittsburgh, PA: Pittsburgh University Press. 
Dane. (2005). Boletín censo general 2005. Perfil Chocó. Recuperado de http://www.dane.gov.co/ files/censo2005/perfiles/choco/choco.pdf

Franco, J. (1977). Modernización, resistencia y revolución. La producción literaria de los años sesenta. Escritura, III(3), 3-20.

Franco, J. (2002). Espectros del Che. Cuadernos de Literatura, 8(15), 89-105.

Gaitán, E. (1995). Grandes del Chocó, Tomo II (M-Z). Medellín: Editorial Alas Libres Ltda.

Garavito, J. (1997). En busca de una identidad cultural colombiana: Changó, el gran putas, de Manuel Zapata Olivella. Thesaurus: Boletín del Instituto Caro y Cuervo, 52(1-3), 320-329.

Harris, M. (1991). Entrevista con Manuel Zapata Olivella. Afro-Hispanic Review, 10(3), 59.

Henao Restrepo, D. (2010). Los hijos de Changó. La epopeya de la negritud en América. En: Zapata Olivella, M. Changó, el gran putas (pp. 11-29). Bogotá: Ministerio de Cultura

Henao Restrepo, D. (2011). La marca de África. La negritud en la novela colombiana. Revista Poligramas, (35), 3-20.

Heredia, A. (1987). Figuras arquetípicas y la armonía racial en Chambacú: corral de negros, de Manuel Zapata Olivella. Afro-Hispanic Review, 6(2), 3-8.

Jiménez, B. (2002). El escritor afro-hispano y el proceso creativo. Afro-Hispanic Review, 21(1-2), 3-8.

Krakusin, M. (2001). Conversación informal con Manuel Zapata Olivella. Afro-Hispanic Review, $X X(1), 15-28$.

Kooreman, T. (1987). Integración artística de la protesta social en las novelas de Manuel Zapata Olivella. Afro-Hispanic Review, 6(1), 27-30.

Leal, C. (2007). Recordando a Saturio. Memorias del racismo en el Chocó (Colombia). Revista de Estudios Sociales, (27), 76-93.

Lima Santos, D. (2014). Abdias do Nascimento y Manuel Zapata Olivella: intelectuales del siglo $\mathrm{XX}$ en el sendero de la discursividad ancestral yoruba y bantú. Estudos de literatura brasileira contemporânea, (44), 223-248. 
Maddox, J. (2016). Una falla geológica de fallas raciales: el Sur norteamericano en Piri Thomas y Manuel Zapata Olivella. Visitas al Patio, (10), 13-40. DOI: https://doi.org/10.32997/20270585-vol.0-num.10-2016-1786

Maddox, J. (2016). Nuevo Muntu, Atlántico Negro: Manuel Zapata Olivella, precursor de Paul Gilroy. En W. Mina Aragón, (Ed). Manuel Zapata Olivella. Un legado intercultural: Perspectiva intelectual, literaria y política de un afrocolombiano cosmopolita (pp. 143-150). Bogotá: Desde Abajo.

Mina Aragón, W. (2016). Entrecruzamiento de saberes en la vida y obra de Manuel Zapata Olivella. En: Manuel Zapata Olivella. Un legado intercultural: Perspectiva intelectual, literaria y política de un afrocolombiano cosmopolita. (pp. 21-71). Bogotá: Desde Abajo.

Martínez de Varela, T. (2009). Mi Cristo Negro. Medellín: Fondo Rotatorio Policía Nacional.

Mose, K. E. (1988). Changó, el gran putas y el negro en la novelística del colombiano Zapata Olivella. Afro-Hispanic Review, 7(1,2,3), 45-48.

Mosquera Rivas, H. (2016). La visibilización de un mártir en El fusilamiento del Diablo. En W. Mina Aragón, (Ed). Manuel Zapata Olivella. Un legado intercultural: Perspectiva intelectual, literaria y política de un afrocolombiano cosmopolita. (pp. 465-474). Bogotá: Desde Abajo.

Múnera, A. (2005). Fronteras imaginadas. Bogotá: Editorial Planeta.

Múnera, A. (2010). Manuel Zapata y la nación inclusiva. En: Manuel Zapata Olivella, por los senderos de los ancestros. Textos escogidos, 1940-2000 (pp. 11-43). Bogotá: Biblioteca de Literatura Afrocolombiana Vol. XVIII, Ministerio de Cultura.

Ortega, J. (2002). La muerte de Artemio Cruz y el relato de la des-fundación nacional. Hispania, 85(2), 198-208.

Ortiz, L. (2001). La obra de Manuel Zapata Olivella: Raza, poética y sociedad. Afro-Hispanic Review, 20(1), 29-35.

Palacios, G. P. (2018). De rebeldías y revoluciones: perspectivas críticas desde abajo y desde Oriente en el pensamiento de Manuel Zapata Olivella. Estudios de Literatura Colombiana (42), 117-138.

Prescott, L. E. (2016). Negritud, mestizaje e identidad: Tres claves en la vida y obra de Manuel 
Zapata Olivella. En: W. Mina Aragón, (Ed). Manuel Zapata Olivella. Un legado intercultural: Perspectiva intelectual, literaria y política de un afrocolombiano cosmopolita (pp. 99-113). Bogotá: Desde Abajo.

Quijano, A. (2000). ¡Qué tal raza! Revista del CESLA. International Latin American Studies Review, (1), 192-200.

Rama, Á. (2005). El boom en perspectiva. Signos literarios, (1), 161-208.

Rank, O. (2015). The Myth of the Birth of the Hero: A Psychological Exploration of Myth. Baltimore-London: JHU Press.

Renaud, M. (2009). Epicidad y heroísmo en la literatura hispanoamericana. Centre de Recherches Latino-Américaines (CRLA Archivos), Équipe ITEM (CNRS-ENS-Université de Poitiers).

Renteria Salazar, Y. (2013). Construcción de identidad regional en la prensa escrita de Quibdó: representaciones sobre ser chocoano. Tesis Doctoral, Universidad Nacional de Colombia.

s/a. (1984). Minería: El renacer de Mineros del Chocó. Síntesis económica, (240), 7-23.

Tillis, A. D. (2005). Manuel Zapata Olivella and the "darkening” of Latin American literature. Missouri: University of Missouri Press.

Tillis, A. D. (2006). Changó, el gran putas de Manuel Zapata Olivella: un volver a imaginar y localizar Haití y su revolución mediante una alegoría postcolonial. Afro-Hispanic Review, 25(1), 105-114.

Valero, S. (2015a). Introducción. Literatura y "afrodescendencia": identidades políticas en la literatura afrolatinoamericana del siglo XXI. Revista de Crítica Literaria Latinoamericana, (81), 9-17.

Valero, S. (2015b). Afroepistemología y sensibilización en las narrativas históricas afrodescendientes del siglo XXI. En S. Valero y A. Campos García (Eds.). Identidades políticas en tiempos de afrodescendencia: auto-identificación, ancestralidad, visibilidad y derechos humanos (pp. 531-577). Buenos Aires: Corregidor.

Valero, S. (2020). "Los negros se toman la palabra”. Primer Congreso de la Cultura Negra de las Américas: debates al interior de las comisiones y plenarias. Bogotá-Cartagena: Pontificia Universidad Javeriana, Universidad de Cartagena, CEA.

Varas, P. (2013). Che, Intertextuality, Memory, and the Power of Images. CineAction, 92, 33-40. 
Velásquez, R. (1992). Las memorias del odio. Bogotá: Colcultura.

Wade, P. (2007). Gente negra, nación mestiza. Dinámicas de las identidades raciales en Colombia. Bogotá: Ediciones Uniandes, Siglo del Hombre Editores.

Wade, P. (2006). Etnicidad, multiculturalismo y políticas sociales en Latinoamérica: poblaciones afrolatinas (e indígenas). Tabula Rasa, (4), 59-81.

Williams, R. y Medrano, J. M. (2018). 90 años de la novela moderna en Colombia (1927-2017). Bogotá: Desde Abajo.

Zapata Olivella, M. (2002). El árbol brujo de la libertad: África en Colombia: orígenes, transculturación, presencia, ensayo histórico-mítico. Valle: Universidad del Pacífico.

Zapata Olivella, M. (1997). La rebelión de los genes: el mestizaje americano en la sociedad futura. Bogotá: Altamir.

Zapata Olivella, M. (1992). Changó, el gran putas. Bogotá: Rei Andes.

Zapata Olivella, M. (1986). El fusilamiento del diablo. Bogotá: Plaza \& Janes. 